\title{
Do Carrots Make You Strong? Motivational And Teamwork Effects of Gamification of Professional DEVELOPMENT FOR FIRST YEAR ENGINEERING STUDENTS
}

\author{
Mike Klassen ${ }^{I}$, Jason Bazylak ${ }^{2}$, Patricia K. Sheridan ${ }^{1}$, Albert Huynh ${ }^{1}$ \\ ${ }^{I}$ Institute for Leadership Education in Engineering \\ ${ }^{2}$ Department of Mechanical and Industrial Engineering \\ University of Toronto \\ mike.klassen@utoronto.ca
}

\begin{abstract}
There is an increasing interest in developing leadership capacity among engineering students, but these efforts are often split between curricular and cocurricular initiatives. This paper reports on an attempt to bridge these two worlds by using in-class incentives for first-year students to participate in leadership workshops. Findings are that team leaders participate at higher than average rates, that students surveyed had attended a large number of workshops and gave on average more detailed feedback than previous cohorts. However, there was no major evidence of greater team-member effectiveness among those who participated in workshops.
\end{abstract}

Keywords: Professional development, engineering leadership, motivation, teamwork, engineering design

\section{INTRODUCTION}

Engineering education is intense, rigorous and challenging, as students simultaneously learn the fundamental mathematical and engineering sciences, and the disciplined practice of engineering design. Professional accreditation of engineering in Canada requires a minimum number of courses in certain subject areas, which creates a dilemma for curriculum designers: With increasing demand for entrepreneurship, leadership and teamwork skills, how do we avoid "curriculum creep" while still meeting accreditation requirements?

To date, the main approach taken by universities in Canada and the United States has been to develop cocurricular and elective leadership development opportunities that fall "outside" the core curriculum which is bound by accreditation [1], [2], [3]. At the same time, others have sought to integrate leadership learning into core courses, particularly engineering design courses which tend to have a stronger teamwork element in their curriculum [4]-[6]. Much less is known about how to bridge the curricular and co-curricular elements. At the University of Toronto, educators are working from both angles: from the core design courses "out" and from the peripheral co-curricular programs "in".

Just because employers and the accreditation board want to see students develop their teamwork, professionalism, leadership and communication, doesn't mean students do. The effects of an intense curriculum and breakneck pace of study can limit the time and interest students have to develop themselves and grow beyond their technical expertise.

One approach to motivating students is to "gamify" optional professional development activities so students can earn grades in core courses and see their progress towards this 'tangible' reward. This concept was documented in 2014 [7] and tested over the past 4 years. Recently the scheme was applied more intentionally to a series of co-curricular leadership workshops, causing participation to surge substantially compared to the previous year, prompting this pilot research study. In this paper, we investigate the effects of this grade incentive on student motivation and team-member effectiveness in a first-year engineering design course.

\section{LITERATURE REVIEW}

We know from earlier research that the activities of engineering students outside the classroom have a significant effect on their engineering and leadership skills and identity, among other outcomes [3], [8]. The dilemma for engineering educators, who largely teach mandatory courses, is that by definition these 'outside the classroom' activities are not for credit. At the same time, engineering leadership educators are concerned that students who choose to participate in their programs are already high skill and high will - and those who need it the most simply choose not to engage. 
This highlights a gap in the research on how curricular and co-curricular learning experiences connect. This study seeks to explore how course instructors can encourage students to take advantage of the many opportunities available to them. It builds on the earlier work on gamification of professional development [7] and an ongoing experiment in a large first year engineering design course to answer two research questions:

(1) What are the motivations of students who attend co-curricular leadership workshops and receive professional development "points" for their participation?

(2) How does their participation in these optional workshops on teamwork and leadership affect their performance in teams in a design course?

In order to conceptualize individual team-member effectiveness, we draw on extensive previous research that developed into a team-effectiveness inventory [6], [9]. This inventory "categorizes individual competencies into three aspects: Relational, Organizational, and Communication. The Relational competencies deal with fostering positive interpersonal relations, the Organizational competencies with managing the workflow of the team, and the Communication competencies with the way in which issues and work are presented and discussed" [6, p. 3]. Based on this inventory, a set of 12 individual competencies have been refined and validated, and integrated into an online tool enabling students to give feedback to each of their teammates on all competencies, complemented by openended comments. This approach to peer feedback was strengthened after a study on feedback by teaching assistants (TAs) concluded that "many of the competencies of the framework are not assessable by observers outside of the team, and that during normal tutorial work periods TAs are only able to assess the functionality of a team as a whole rather than the effectiveness of each individual team member" [10, p. $11]$.

\section{PROGRAMMATIC CONTEXT}

In the 2016-2017 academic year, nearly 900 first year engineering students enrolled in a first-year design course were incentivized to participate in various professional development (PD) activities through the use of PD 'points'. Through attending and answering in-lectures questions students are evaluated on $3-5 \%$ of their final course grade. Optional events deemed by the Course Coordinator to help students develop professionally, are allocated a PD bonus point value based on the time commitment. For instance, attending a 1 hour Engineers Without Borders seminar on the place of the engineer in the global word might earn 1 "bonus PD point." A day long leadership seminar may earn the student 3 bonus PD points. These bonus points earn back grades lost to incorrect answers or missed lectures. Each bonus PD point is worth about $1 / 10$ to $1 / 8$ of a percent. PD-point events are advertised to the students through a pre-lecture slideshow (run for 20 minutes before the 9 am lecture while students find their seats) and through Learning Management System announcements.

One of the activities included in this scheme is a series of drop-in leadership workshops designed specifically for engineering students. The leadership workshops were offered in a new format in 2015-2016 as optional, drop-in, stand-alone sessions. However, the workshops had low attendance - with a total of average attendance of 10.2 students per event, over 23 events, for a total of 235 "attendances". In contrast, in 2016-2017, the average attendance surged to 38.4 students per event, over 20 events, for a total of 769 "attendances". Overall, 53\% of workshop attendees over the year were eligible to earn PD points. Based on an analysis of the demographics of attendees, we believe that the PD Points intervention played a major role in this increase in attendance either through incentivizing with grades or the direct marketing channel of the Learning Management System announcements.

\section{DATA COLLECTION}

This study uses two sources of data to answer the two research questions. First, a very short survey was developed for first year students who attend leadership workshops in the Winter 2017 term. The survey included questions about motivations to participate in the leadership workshop, and whether students would consent to us linking their survey response to their teameffectiveness feedback from the course. This survey was implemented in two workshops (out of 20 for the year), and 19 unique students responded to the survey. The topic of the first workshop was Giving and Receiving Feedback while the second focused on Stress Management. This data is additionally supplemented by anonymous feedback forms collected from attendees as part of the leadership workshop program evaluation.

The second source of data is the previously mentioned online team-effectiveness learning system, which gathers self-and-peer feedback on student behaviour in the team project for the first-year design course. With permission from 16 of 19 workshop participants, we were able to access the quantitative and qualitative feedback at two points in time in the term: before the workshops, and after the workshops.

There are some significant limitations to this dataset 
that are important to consider before we shift to our findings. First, the survey was only used for two workshops out of 20 , both of which occurred late in the year. This limits the overall size of our sample. Second, the survey was very short (2 questions) and multiplechoice, which eases analysis but limits opportunity for students to explain a more nuanced set of motivations beyond the boxes offered.

\section{FINDINGS}

The first workshop had 14 attendees who filled out the survey, while the second workshop had 11 completed surveys. Of these 25 "attendances", there were 19 unique individuals -6 of whom attended both workshops.

In response to the question "Let us know why you came to this event today", we had only two students who said "I came only for the bonus" whereas 17 students said they want to develop their professional personal, and the bonus points "Doesn't hurt either".

\begin{tabular}{|l|l|}
\hline I only came for the PD bonus. & 2 \\
\hline I want to develop my professional persona...the & 17 \\
PD Bonus doesn't hurt either. & \\
\hline $\begin{array}{l}\text { I want to develop my professional } \\
\text { persona... what does "PD Bonus" mean }\end{array}$ & \\
anyway? & \\
\hline
\end{tabular}

Of the 19 individuals, 16 consented to connect their workshop survey response with their team-effectiveness data from the course. For all 16 of these consented responses, we read through the qualitative comments on their team-effectiveness and analyzed the quantitative dimensions of the feedback they received from their teammates. We also looked at their attendance at the wider suite of leadership workshops offered throughout the year.

The first-year workshop participants we surveyed attended an average of 6.5 workshops over the course of the year. This compares to an average attendance of 1.9 workshops for the entire population of students who attended leadership workshops.

From the anonymous workshop program feedback forms, out of a total of 44 responses (from the two workshops in question) 22 indicated that their primary motivation for attending was for personal reasons, 14 for some form of credit (i.e. PD points), and 8 who had no or other responses. When asked via a retrospective pre-post Likert scale for their change of knowledge through each workshop, an equivalent of $50 \%$ of students indicated significant knowledge acquisition ("not very knowledgeable" to "very knowledgeable"). For the workshop on Giving and Receiving Feedback specifically, 12 out of 20 responses indicated that their primary intended application of the material would be in their engineering course team project work.

From the quantitative team-effectiveness data, we found that the average change in team-effectiveness rating (a score out of 4.0, averaged across all 12 competencies assessed by peers) between mid-term and end-of-term feedback was around -0.1. Students who consented showed either a decrease in their team-effectiveness between the middle and end of the course, or had a better calibration to the behaviourally-anchored rating scale of the inventory in its second use. For a point of comparison, in a previous year when a study invited the entire class' participation, the average change between mid-point and end-point was also around -0.1 . The size of our sample is too small to make claims about statistical significance, but it shows that this group tended to fare about the same as their classmates in their change in team-member effectiveness.

In terms of the open-ended qualitative comments provided by the workshop participants to their team members in the course through the team-effectiveness learning system, students provided more feedback than previously studied classes in their end-of-term feedback. The workshop participants provided an average of 279 characters of feedback, compared to an average of 107 characters of feedback in a 2014 study of students in the same class. While our sample size is small, this too bears future investigation, as it would indicate that students attending workshops, especially on the topic of Giving and Receiving Feedback, are providing more qualitative feedback to their team-members than their classmates.

From the qualitative comments provided to students who attended the workshop, we found that that 6 out of 16 $(40 \%)$ consented respondents were the elected 'team leader' for their project group. Given that the average team size in the course is five to six team members, with only one team leader per team, the percentage of team leaders in the course $(17 \%-20 \%)$ is much lower than the proportion who attended the leadership workshops. We will return to this in the discussion.

Finally, from an analysis of qualitative comments on team-effectiveness, we noticed two distinct 'types' of effective team leaders (as identified by their peers) among the sample. The first is a highly-organized student who keeps the team on track and step ups to fill in where their teammates need help - usually through taking on more of the work themselves. The second is a process facilitator who gathers input from peers, runs the meetings, but could be more assertive and directive. 


\section{DISCUSSION}

Our first question looked at the motivations for students to attend co-curricular leadership workshops. From their direct responses, students are motivated both intrinsically by the professional development and extrinsically by the PD bonus points which contribute to their grade in a design course in their first year. Looking to the data on their attendance at similar workshops throughout the term, we see that the group surveyed attended many more workshops than the other attendees (6.5 workshops compared to an average of 1.9). This supports their survey responses, as repeated attendance at numerous sessions (including full-day workshops on Saturdays) shows a level commitment that goes beyond the very minor grade percentage available from the bonus points. The anonymous feedback surveys of attendees also support this as 22 out of 44 total survey responses across those the two workshops studied indicated that they attended the workshop primarily for personal learning over extrinsic motivators.

Another interesting pattern in the data is that there was a much higher proportion of team leaders in our sample than in the general population $(40 \%$ vs. $17-20 \%)$. In future surveys or interviews we could probe this to better understand any potential causality - do students who attend many workshops become empowered to be the team leaders for their project? Or do those who get nominated as team leader choose to attend more workshops because they feel the need to develop their skills? Perhaps it is a combination of both.

Our second question looks at the effect of workshop attendance on teamwork and leadership behaviours in the design course. Here we find that on average, our study participants have similar scores on team-effectiveness as the wider class. Where they do differ is in the amount of qualitative feedback they provide to their teammates. While not statistically significant given the small sample size, this is an indication of the potential behavioural impact of the workshops on how students exhibit one specific leadership behavior - giving feedback. On the other hand, there were a handful of examples where the end-of-term feedback provided to workshop participants questioned students' ability to express their ideas clearly, to be direct, and "if you have an issue with a group member make sure you go over it with them and not blow it off". In the anonymous workshop program feedback forms, half of the students indicated significant learning through the workshops (with additional students reporting minor learning), and for the topic of Giving and Receiving Feedback specifically, the majority of students intended to apply the material to their team projects.
This underscores the nuance of giving and receiving feedback - it can differ in-person in real-time when compared to online with ample time for a thoughtful textual response. It also reminds us that teameffectiveness requires integration of a number of skills which need to be built over time and enacted at key moments in real life. Attending workshops on specific topics will not dramatically change behaviours overnight.

\section{CONCLUSION}

This pilot study shows how engineering educators can encourage students to learn professional skills both inside and outside of academic coursework. The demonstrated impact of gamification on student motivations and in particular their increased attendance at co-curricular workshops can potentially be adapted to use in other contexts, such as upper-year courses. To more deeply understand motivations, we plan to include the survey in more workshops next year, particularly in the first term, so that we can compare those who only attend one or two workshops with those who continue to participate throughout the academic year. We also will consider conducting a few short interviews to probe motivations in a more open-ended way beyond the limited options of the survey used in this study.

Our finding that team leaders disproportionately participate in the workshops indicate that it might be worthwhile to explicitly target this group in the future, possibly even using some of the key findings from this pilot study to make an evidence-based case for the benefits of their participation.

The finding that many of the topics of the workshops do not translate neatly into concrete behavioural change in teams is an important reminder for leadership educators that new practices are not instantly adopted by students.

\section{References}

[1] M. Klassen, D. Reeve, C. Rottmann, and R. Sacks, "Charting the Landscape of Engineering Leadership Education in North American Universities," presented at the 2016 ASEE Annual Conference \& Exposition, New Orleans, LA, 2016. [2] R. Paul and L. G. Cowe Falls, "Engineering Leadership Education: A Review of Best Practices," presented at the 2015 ASEE Annual Conference \& Exposition, Seattle, WA, 2015.

[3] D. B. Knight and B. J. Novoselich, "Curricular and Co-curricular Influences on Undergraduate Engineering Student Leadership," J. Eng. Educ., vol. 106, no. 1, pp. 44-70, Jan. 2017.

[4] K. A. Smith, "Cooperative learning: Effective teamwork for engineering classrooms," presented at the 1995 Frontiers in Education Conference, Atlanta, GA, 1995, vol. 1, pp. 13-18. 
[5] R. Lingard and S. Barkataki, "Teaching teamwork in engineering and computer science," in Frontiers in Education Conference (FIE), 2011, 2011, p. F1C-1.

[6] P. K. Sheridan, G. Evans, and D. Reeve, "A Proposed Framework for Teaching Team-effectiveness in Team-based Projects," presented at the 2012 ASEE Annual Conference \& Exposition, San Antonio, TX, 2012.

[7] J. Bazylak, "Gamification of Professional Development for First Year Engineering Students," in Proceedings of the Canadian Engineering Education Association, Canmore, AB, 2014.
[8] C. Rottmann, R. Sacks, M. Klassen, and D. Reeve, "Sports, arts and concrete canoes: Engineers learning to lead outside the for-mal curriculum," presented at the 2016 ASEE Annual Conference \& Exposition, New Orleans, LA, 2016.

[9] P. K. Sheridan, L. E. Gammal, J. P. Ma, G. Evans, and D. Reeve, "A Team-effectiveness Inventory for Guided

Reflection and Feedback," presented at the 2013 ASEE Annual Conference \& Exposition, Atlanta, GA, 2013.

[10] P. K. Sheridan, D. Reeve, and G. Evans, “Understanding Teaching Assistants' Assessment of Individual Teamwork Performance," presented at the 2014 ASEE Annual Conference \& Exposition, Indianapolis, IA, 2014. 